\title{
The Prediction of Concrete Temperature during Curing Using Regression and Artificial Neural Network
}

\author{
Zahra Najafi ${ }^{1}$ and Kaveh Ahangari ${ }^{2}$ \\ ${ }^{1}$ Department of Geology, Engineering Faculty, Science and Research Branch, Islamic Azad University, Poonak Square, Tehran, Iran \\ ${ }^{2}$ Department of Mining Engineering, Engineering Faculty, Science and Research Branch, Islamic Azad University, \\ Toward Hesarak, End of Ashrafi Esfahani, Poonak Square, Tehran 1477893855, Iran
}

Correspondence should be addressed to Kaveh Ahangari; kaveh.ahangari@gmail.com

Received 5 December 2012; Accepted 12 February 2013

Academic Editor: İlker B. Topçu

Copyright (c) 2013 Z. Najafi and K. Ahangari. This is an open access article distributed under the Creative Commons Attribution License, which permits unrestricted use, distribution, and reproduction in any medium, provided the original work is properly cited.

Cement hydration plays a vital role in the temperature development of early-age concrete due to the heat generation. Concrete temperature affects the workability, and its measurement is an important element in any quality control program. In this regard, a method, which estimates the concrete temperature during curing, is very valuable. In this paper, multivariable regression and neural network methods were used for estimating concrete temperature. In order to achieve this purpose, ten laboratory cylindrical specimens were prepared under controlled situation, and concrete temperature was measured by thermistors existent in vibrating wire strain gauges. Input data variables consist of time (hour), environment temperature, water to cement ratio, aggregate content, height, and specimen diameter. Concrete temperature has been measured in ten different concrete specimens. Nonlinear regression achieved the determined coefficient $\left(R^{2}\right)$ of 0.873 . By using the same input set, the artificial neural network predicted concrete temperature with higher $R^{2}$ of 0.999 . The results show that artificial neural network method significantly can be used to predict concrete temperature when regression results do not have appropriate accuracy.

\section{Introduction}

Temperature prediction in fresh concrete is of great interest for designers and contractors because cement hydration is an exothermic process and the heat generation may lead to very early onset of thermal cracks in absence of any load [1]. Therefore, utilizing a method that estimates temperature during curing is very beneficial.

Cement hydration produces a rise in concrete internal temperature. Temperature rise varies by many parameters including cement composition, fineness and content, aggregate content and CTE (coefficient of thermal expansion), section geometry, placement, and ambient temperatures [2]. After reaching the maximum temperature, the temperature of concrete decreases [3].

Pours with a large volume to surface area ratio are more susceptible to thermal cracking. Cements used for mass concrete should have a low $\mathrm{C}_{3} \mathrm{~S}$ and $\mathrm{C}_{3} \mathrm{~A}$ content to reduce excessive heat during hydration. Cement with a lower fineness with slow hydration reduces temperature rise. Mass concrete mixtures should contain as low of a cement content as possible to achieve the desired strength. This lowers the heat of hydration and subsequent temperature rise. A higher coarse aggregate content $(70-85 \%)$ can be used to lower the cement content, reducing temperature rise. The CTE (coefficient of thermal expansion) of the coarse aggregate has the main influence on the CTE of the concrete. Lower CTE aggregates tend to have a higher thermal conductivity; thus, heat is released fast from the core. Lower ambient temperatures produce less temperature rise. Lower volume to surface ratio produces less temperature rise. $W / C$ has a large effect on temperature rise. The lower $W / C$ is, the less temperature rises [2].

Measuring concrete temperature during curing requires instrument and high costs. The used concrete temperature prediction methods commonly consist of The Portland Cement Association (PCA) method, graphical method of ACI 207.2R, Schmidt's method [4], and ConcreteWorks software package [5]. 
The PCA Method calculates $10^{\circ} \mathrm{F}$ temperature rise for every $100 \mathrm{lb}$ of cement, provides no information on time of maximum temperature, does not allow the quantification of temperature differences, and assumes that the least dimension of the concrete member is at least $1.8 \mathrm{~m}(6 \mathrm{ft})$. Graphical method of ACI 207.2R uses charts and equations based on empirical data and assumptions are for boundary conditions. Generally, this method underestimates maximum temperature and is poor predictor of time to achieve maximum temperature. Schmidt's method is little guidance for boundary conditions and difficult to model. Moreover, it can be complicated and should be performed by an experienced engineer [5]. In addition to defects of three above-mentioned methods, they do not predict continuous concrete temperature. ConcreteWorks Software package used for predicting continuous concrete temperature, needs to measure amounts of concrete air content, slump, specified final compressive strength $\left(f_{c}^{\prime}\right)$, coefficient of concrete thermal expansion and thermal properties. This type of measuring spends too much time and cost. Thus, using quick and easy method for prediction of continuous concrete temperature, which measures input parameters in an easy and inexpensive way, could be very useful.

The aim of this study is predicting the temperature during concrete curing by use of time ( $h$ ), environment temperature, water to cement ratio, aggregate content, diameter, and specimen height as variables. The required data are a result of laboratory experiment. Multivariate regression (SPSS software) and artificial neural network (MATLAB) have been used for prediction.

\section{Experimental Procedures}

In order to predict temperature during concrete curing, it is required to measure the temperature continuously using the thermistors, which are located inside the concrete samples. The necessary data is obtained from ten experiments carried out on different cylindrical concrete specimens in the Institute of Geotechnical Engineering and Mine Surveying of Technical University of Clausthal, Germany. Different types of vibrating wire strain gauges were installed in each concrete specimen. The vibrating wire strain gauges are equipped with thermistors, and the concrete temperature was measured by it. During different stages of concreting in the concrete was appropriately compacted by a manual vibrator.

The measuring began right after specimen concreting and during the curing process. Temperature was recorded until 30 hours after concreting, which the temperature changes were rather stopped.

In order to predict the temperature more accurately, measured concrete temperature in specimens with similar strain gauges possibility was utilized as concrete temperatures.

The type of cement used in this study and produced by German Deuna Co. is a Portland cement (CEM I, 42.5R).

The characteristics of specimens are presented in Table 1. The used aggregates in all specimens are coarse and silica type. Specimen no. 9 was put in cold weather $\left(-2^{\circ} \mathrm{C}\right.$ until $+1.84^{\circ} \mathrm{C}$ ) after concreting and during the curing process. For
TABLE 1: Characteristics of experimental specimens for set $I$.

\begin{tabular}{lcccc}
\hline $\begin{array}{l}\text { Specimen } \\
\text { no. }\end{array}$ & $W / C(\%)$ & $\begin{array}{c}\text { Diameter } \\
(\mathrm{mm})\end{array}$ & $\begin{array}{c}\text { Height } \\
(\mathrm{mm})\end{array}$ & $\begin{array}{c}\text { Aggregate } \\
(\mathrm{Kg})\end{array}$ \\
\hline 1 & 50 & 460 & 480 & 91.458 \\
2 & 50 & 300 & 480 & 91.458 \\
3 & 50 & 200 & 480 & 91.458 \\
4 & 67 & 300 & 480 & 44 \\
5 & 50 & 300 & 250 & 87.772 \\
6 & 50 & 200 & 250 & 87.772 \\
7 & 67 & 460 & 480 & 42.48 \\
8 & 61 & 460 & 480 & 43.327 \\
9 & 65 & 460 & 480 & 88 \\
10 & 50 & 460 & 480 & 87.772 \\
\hline
\end{tabular}

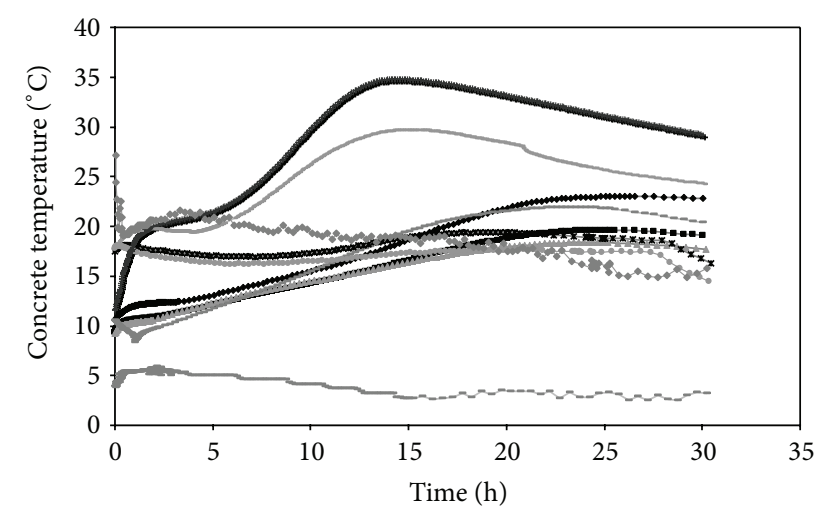

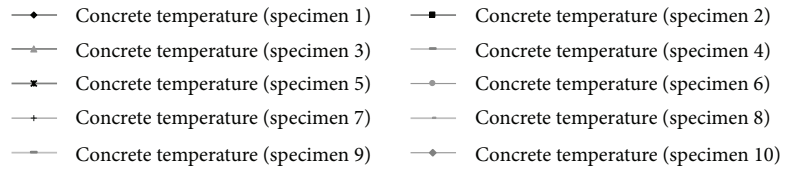

FIGURE 1: Measured temperature changes during curing for concrete specimens.

specimens with water to cement ratio of $50 \%$ and specimen no. 9 (concreting in cold weather), $30 \mathrm{~mL}$ plasticizer was used for each kilogram of cement.

The measured temperature changes during curing for specimens are presented in Figure 1.

\section{Data Analysis and the Results}

3.1. Multivariable Regression. In this study, both linear and nonlinear regressions were used to develop equations between concrete temperature and input variables. The stepwise variable selection procedure was applied to prepare equations. The statistical parameters of the input variables are shown in Table 2.

By using the least square mathematical method, the intercorrelations of time $(h)$, environment temperature, water to cement ratio $(W / C)$, aggregate content, specimen height, and diameter with concrete temperature were calculated at 0.486 , $0.704,0.181,-0.617,0.032$, and 0.228 , respectively. The results show that with the increase of environment temperature and 
TABLE 2: The range of variables.

\begin{tabular}{|c|c|c|c|c|c|}
\hline Variable (\%) & Minimum & Maximum & Mean & Standard deviation & Number of data \\
\hline Time (hour) & 0.00 & 30.433 & 10.12 & 9.049 & 2340 \\
\hline Environment temperature $\left({ }^{\circ} \mathrm{C}\right)$ & -2 & 22.48 & 15.496 & 6.142 & 2340 \\
\hline Water/cement ratio (\%) & 50 & 67 & 58.62 & 7.36 & 2340 \\
\hline Aggregate weight (kg) & 42.48 & 91.458 & 67.17 & 23.14 & 2340 \\
\hline Diameter (mm) & 200 & 460 & 396.68 & 96.57 & 2340 \\
\hline Height (mm) & 250 & 480 & 452.58 & 74.55 & 2340 \\
\hline
\end{tabular}

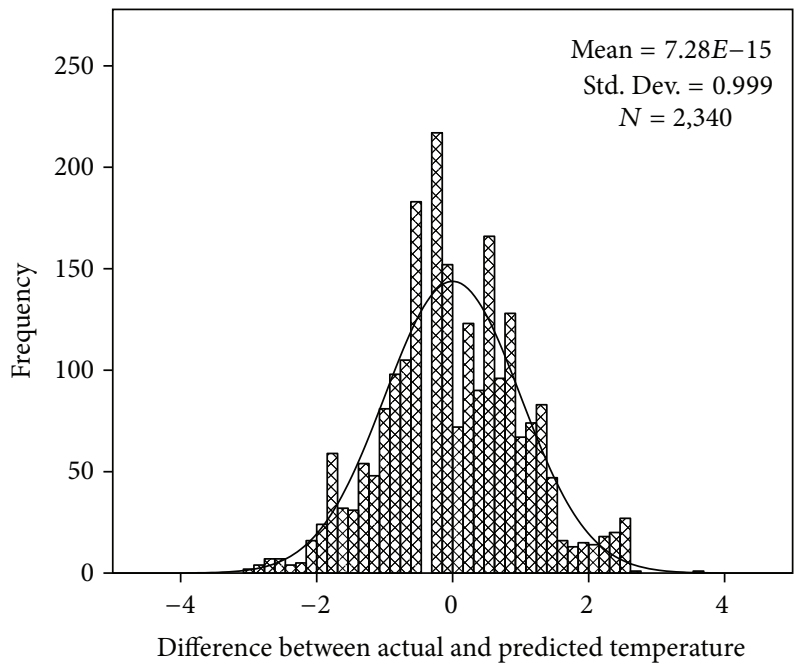

FIGURE 2: Distribution of the difference between actual temperature values and predicted temperature values obtained from multivariate regression (1).

time lapse, concrete temperature rises, and with the increase of aggregate content, concrete temperature decreases. The effect of other parameters on concrete temperature is not significant.

The linear equation between input variables and concrete temperature is as follows:

$$
\begin{aligned}
T= & 12.425+0.32 t+0.694 T_{\text {out }}-0.064\left(\frac{W}{C}\right) \\
& -0.107 g+0.028 d-0.018 h, \quad R^{2}=0.814 .
\end{aligned}
$$

In addition, the nonlinear equation between parameters is as follows:

$$
\begin{aligned}
T= & -21.95+0.946 t+1.731 T_{\text {out }}-0.356\left(\frac{W}{C}\right) \\
& +1.705 g+0.02 d-0.007 h-0.026 t^{2}-0.203 T_{\text {out }}^{2} \\
& -0.014 g^{2}+0.007 T_{\text {out }}^{3}, \quad R^{2}=0.873,
\end{aligned}
$$

in which $t, T_{\text {out }}, g,(W / C), d$, and $h$ are time $(h)$, environment temperature $\left({ }^{\circ} \mathrm{C}\right)$, aggregate amount $(\mathrm{Kg})$, water to cement ratio, concrete specimen diameter $(\mathrm{mm})$, and height $(\mathrm{mm})$, respectively.

The distribution of the difference between concrete temperature predicted from (1) and (2), and actual determined

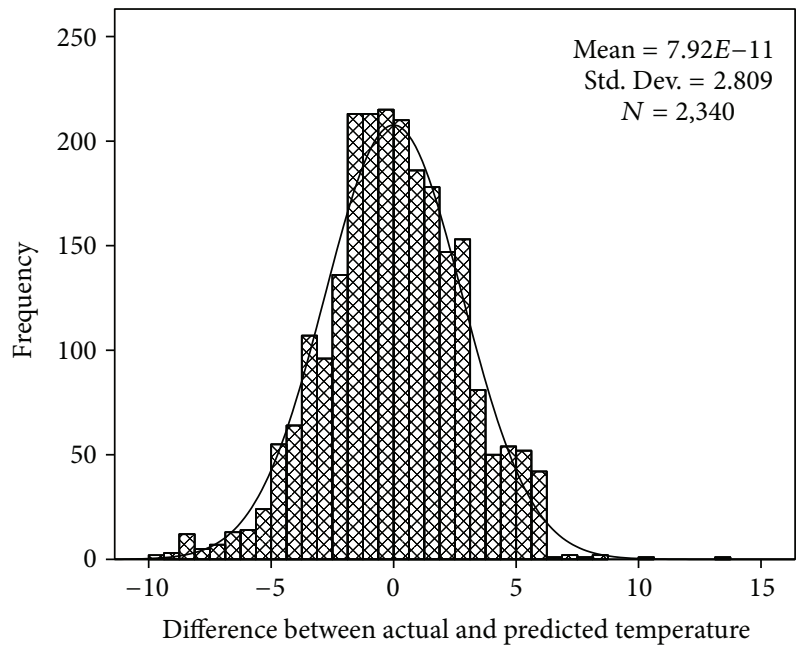

FIGURE 3: Distribution of the difference between actual temperature values and predicted temperature values obtained from multivariate regression (2).

amounts are shown in Figures 2 and 3. The results indicate that (2) can have a significant estimation of concrete temperature during curing for concrete made from CEM $I, 42.5 R$.

3.2. Artificial Neural Network Procedure. Among the existing numerous neural networks (NNs) paradigms, feed-forward artificial neural networks (FANNs) are the most popular due to their flexibility in structure, good presentational capabilities, and large number of available training algorithms [6-8].

The basic structure of a multilayer feed-forward network model can be made of one input layer, one or more hidden layers, and one output layer [9].

Neural network training can be made more efficient by specific preprocessing. In this paper, all the input and output parameters were preprocessed by normalizing inputs and targets; therefore, in the preprocessing stage, their mean and standard deviation are 0 and 1, respectively. Consider the following:

$$
N_{p}=\frac{\left(A_{p}-\operatorname{mean} A_{p s}\right)}{\operatorname{std} . A_{p}},
$$

in which $A_{p}$ is an actual parameter, mean $A_{p s}$ is actual parameters mean, std. $A_{p}$ is actual parameters standard deviation, and $N_{p}$ is a normalized parameter [10]. 
TABLE 3: Details of ANN model.

\begin{tabular}{lcccccc}
\hline Input sets & $\begin{array}{c}\text { Training } \\
\text { set size }\end{array}$ & $\begin{array}{c}\text { Testing set } \\
\text { size }\end{array}$ & $\begin{array}{c}\text { Validation } \\
\text { set size }\end{array}$ & $I$ & $J$ & $K$ \\
\hline $\begin{array}{l}t, T_{\text {out }},(W / C), \\
g, d, h\end{array}$ & 1404 & 468 & 468 & 5 & 6 & 6 \\
\hline
\end{tabular}

$I$ : number of input nodes, $J$ : number of nodes in the first hidden layer, and $K$ : number of nodes in the second hidden layer.

TABLE 4: Statistical analysis of predicted temperature and the generalized performance of ANN-based model.

\begin{tabular}{lcc}
\hline & Validation stage & Training stage \\
\hline Correlation coefficient & 0.9996 & 0.9993 \\
\hline
\end{tabular}

In this part of the study, ANN model is presented to predict concrete temperature during curing. Multilayer feedforward network model has been trained with BP (back propagation) training algorithm.

Different neural networks were designed, and the best parameters value was obtained by trial and error. However, the main aim is to acquire a neural network with the smallest dimensions and the least errors. The most appropriate results have been obtained from chosen network model in which hyperbolic tangent sigmoid and linear functions were used as an activation function for the hidden and output layer neurons. According to (1), the selected variables were determined as the best variables for predicting concrete temperature. Therefore, those variables, which were used as input to ANN for the improvement of concrete temperature prediction, are listed in Table 3.

The data in the model were separated into three: training, validation, and test sets in which the test set was used after training. The validation and training process were stopped after 245 epochs for model.

The performance function is the mean square error (MSE), the average-squared error between the network predicted outputs and the target outputs, which are equal to 0.00044 for training. The correlation coefficients for the validation and training stages are presented in Table 4.

Figures 4, 5, and 6 show a graphical comparison of the determined experimental temperature and those predicted by artificial neural network in the validation, training, and test process for model.

The distribution of the difference between predicted temperature by ANN and actual values in the test process is presented in Figure 7.

It was observed that concrete temperature prediction using ANN procedure could be more acceptable and satisfactory than others.

\section{Conclusions}

(i) Concrete temperature during curing was studied by experimenting on ten cylindrical concrete specimens under controlled situations in which the concrete temperature was measured by strain gauges (which are equipped with thermistor). Data recording began

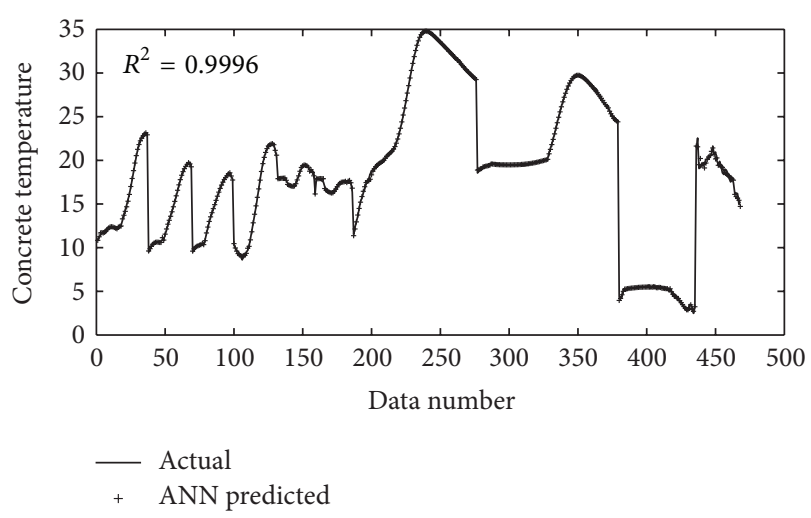

FIGURE 4: Graphical comparison of temperature with those predicted by ANN in the validation process.

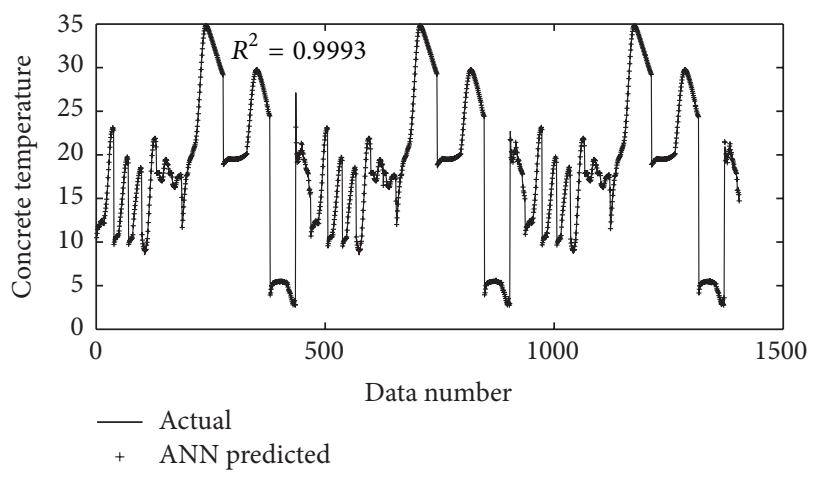

FIGURE 5: Graphical comparison of temperature with those predicted by ANN in the training process.

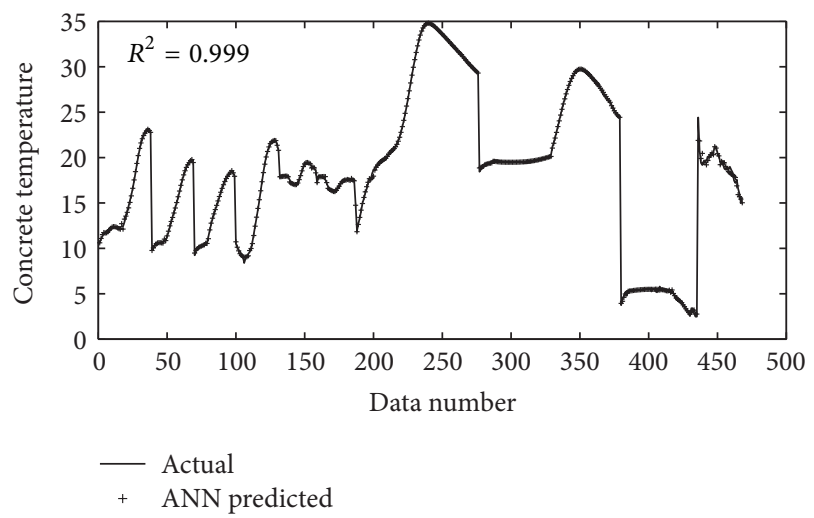

FIGURE 6: Graphical comparison of temperature with those predicted by ANN in the test process.

right after specimen concreting and continued until 30 hours after.

(ii) The model used for concrete specimens, which were prepared with Portland cement (CEM I, 42.5R), was utilized for estimating concrete temperature using stepwise regression and artificial neural network methods. 


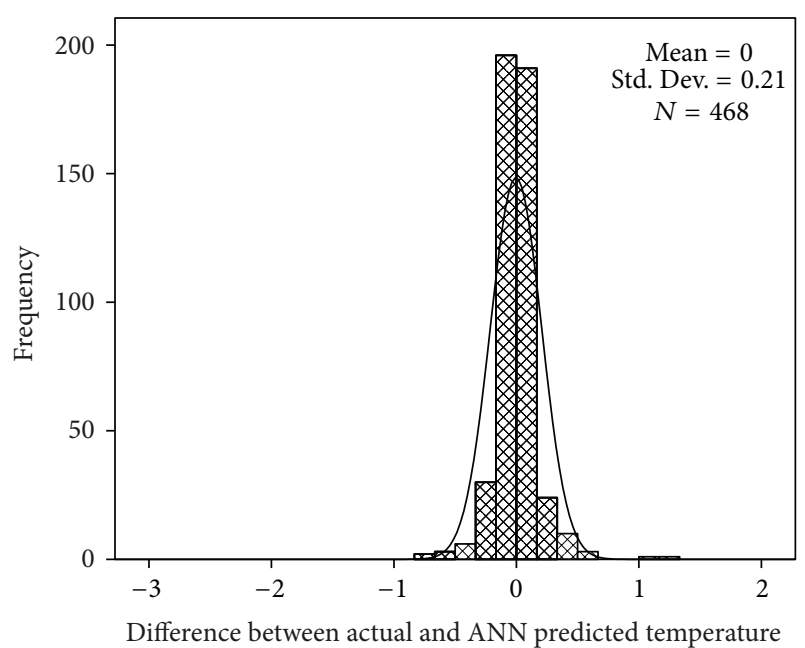

FIGURE 7: Distribution of the difference between predicted temperature by ANN and actual values in the test process.

(iii) The inter correlation between input variables and concrete temperature showed that higher environment temperature and time in concrete can result in higher concrete temperature and higher aggregate content in concrete results in lower-concrete temperature. No other parameters were significant.

(iv) The linear and nonlinear equations can estimate the concrete temperature with correlation coefficients $\left(R^{2}\right)$ of 0.814 and 0.873 , respectively.

(v) The artificial neural network procedure can predict the concrete temperature with correlation coefficient of 0.999 . Therefore, the obtained results are much better than multivariate regression.

(vi) The results show that artificial neural network is a reliable method to predict concrete temperature during curing.

\section{Conflict of Interests}

Hereby, the authors disclosure that this paper was just a contribution to the advancement of science, and they just used SPSS and MATLAB softwares as the mathematical methods for prediction. The authors do not have a direct financial relation with the commercial identity mentioned in the paper (SPSS and MATLAB softwares).

\section{References}

[1] P. F. Siew, T. Puapansawat, and Y. H. Wu, "Temperature and heat stress in a concrete column at early ages," ANZIAM Journal, vol. 44, no. E, pp. C705-C722, 2003.

[2] R. Moser, "Mass Concrete, CEE8813A-Material science of concrete. 2. Lecture Overview," http://people.ce.gatech .edu/ kk92/massconcrete.pdf.

[3] H. Weigler and S. Karl, Junger Beton: Beanspruchung-FestigkeitVerformung, vol. 40, Betonwerk Fertigteil-Technik, 1974.
[4] K. A. Riding, J. L. Poole, A. K. Schindler, M. C. G. Juenger, and K. J. Folliard, "Evaluation of temperature prediction methods for mass concrete members," ACI Materials Journal, vol. 103, no. 5, pp. 357-365, 2006.

[5] ConcreteWorks, IHEEP Conference, San Antonio, Tex, USA, 2009.

[6] C. T. Leondes, Neural Network Systems Techniques and Applications: Algorithms and Architectures, Academic Press, New York, NY, USA, 1998.

[7] R. P. Lippmann, "An introduction to computing with neural nets," IEEE ASSP Magazine, vol. 4, no. 2, pp. 4-22, 1987.

[8] D. Sarkar, "Methods to speed up error back-propagation learning algorithm," ACM Computing Surveys, vol. 27, no. 4, pp. 519542, 1995.

[9] F. Özcan, C. D. Atiş, O. Karahan, E. Uncuoğlu, and H. Tanyildizi, "Comparison of artificial neural network and fuzzy logic models for prediction of long-term compressive strength of silica fume concrete," Advances in Engineering Software, vol. 40, no. 9, pp. 856-863, 2009.

[10] H. Demuth and M. Beale, Neural Network Toolbox for Use with MATLAB, Handbook, 2002. 

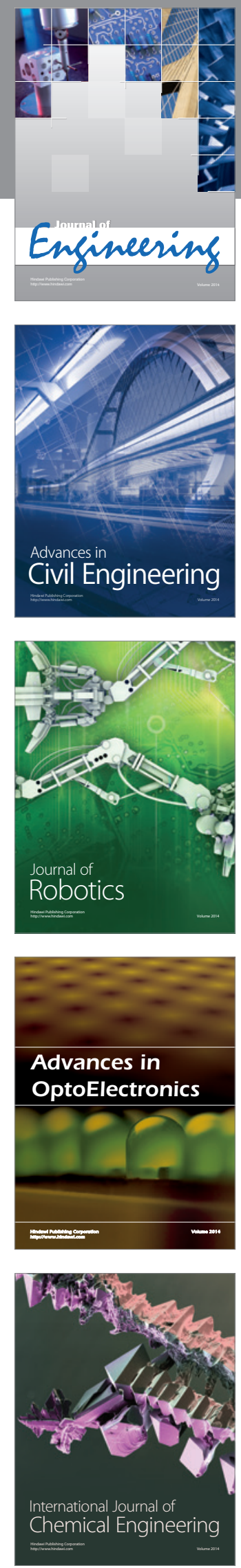

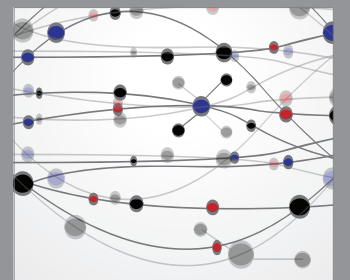

The Scientific World Journal
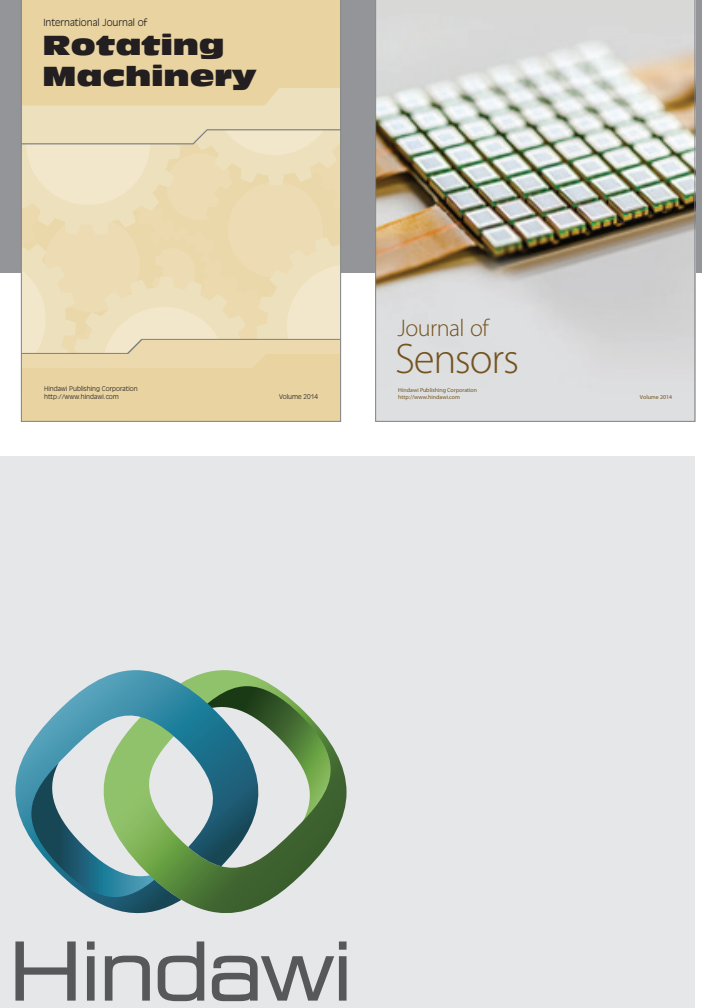

Submit your manuscripts at http://www.hindawi.com
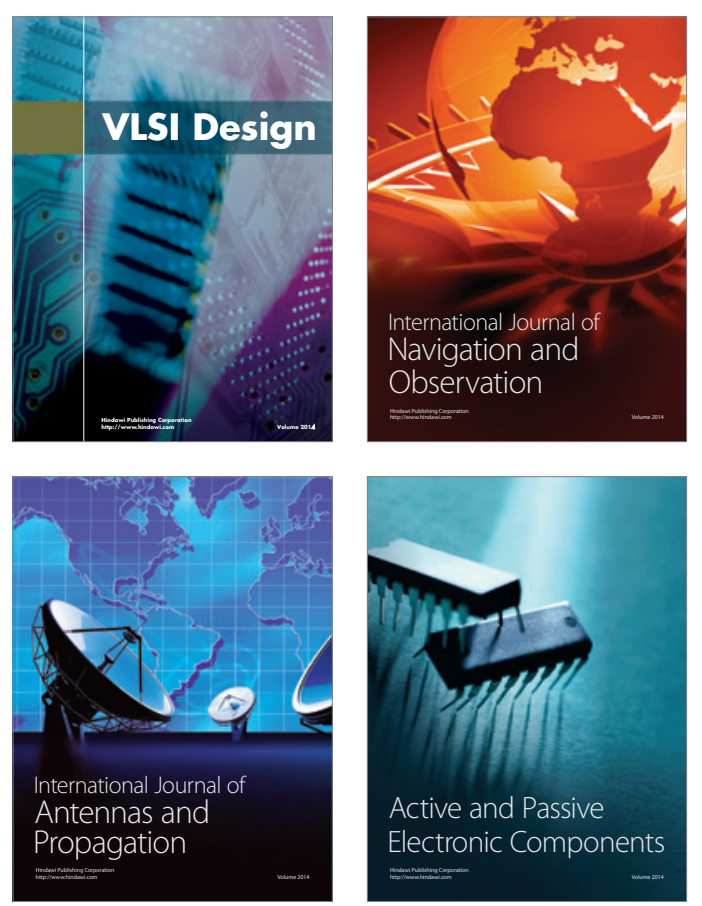
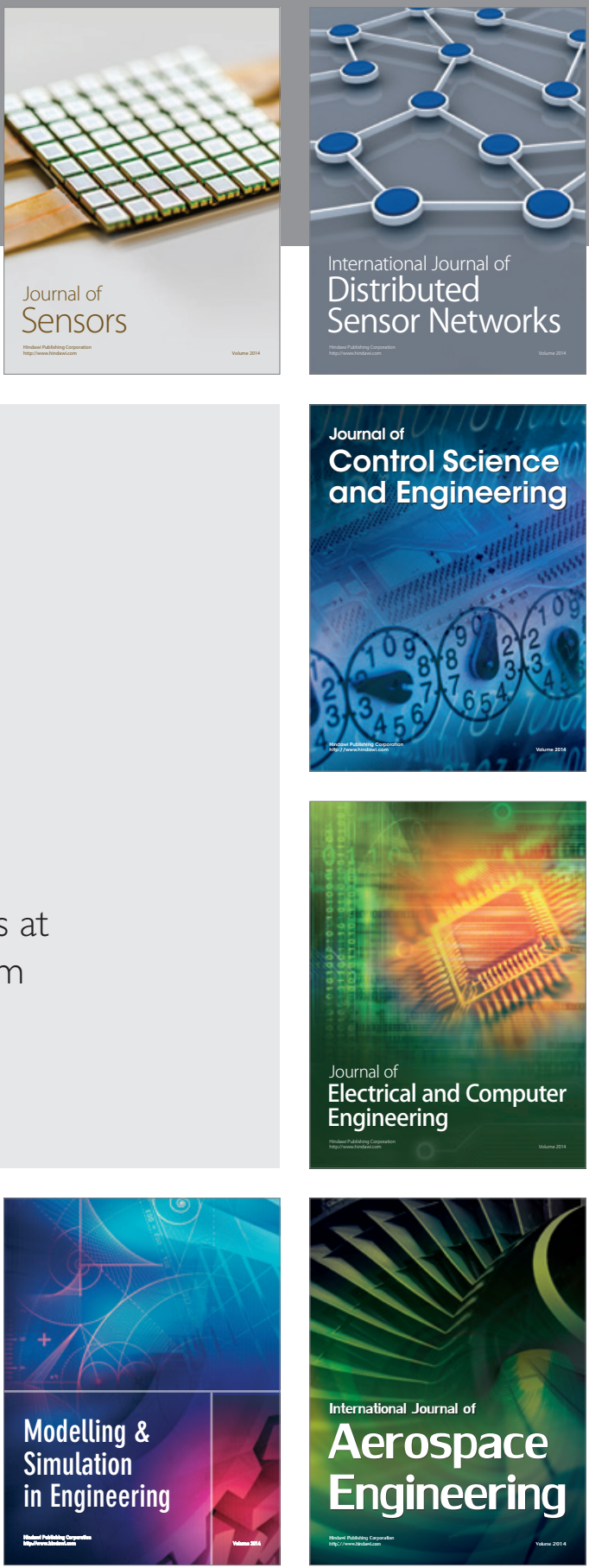

Journal of

Control Science

and Engineering
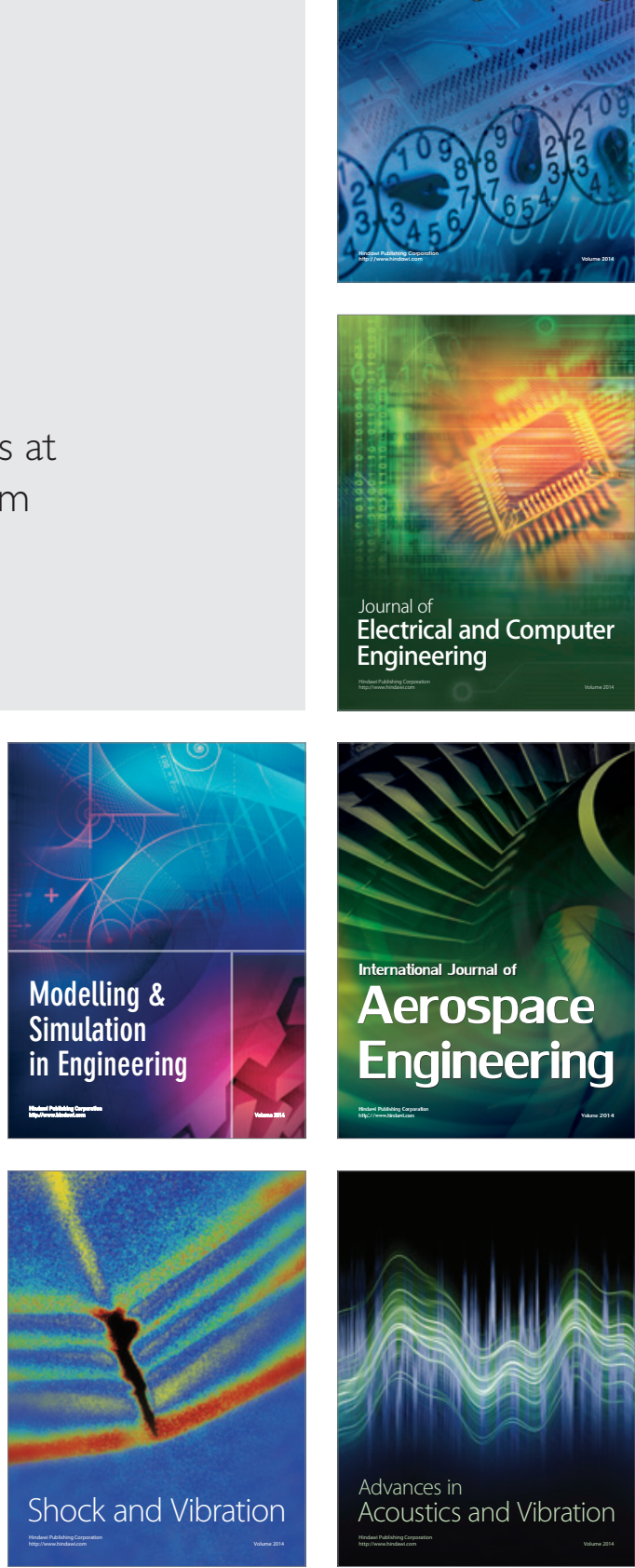